\title{
THE STANDARD OF MANAGEMENT AND APPLICATION OF CULTURAL HERITAGE DOCUMENTATION
}

\author{
YEN YA NING ${ }^{1}$, WENG KUO HUA ${ }^{2}$, CHENG HUNG MING ${ }^{3}$, HSU WEI SHAN ${ }^{4}$ \\ China University of Technology, ${ }^{1}$ Faculty of Architecture, ${ }^{2,3}$ Faculty of Interior Design, ${ }^{4}$ Graduate \\ Student of Architecture
}

No.56, Sec. 3, Singlong Rd., Wunshan District, Taipei City 116, Taiwan (R.O.C.)

alexyen@cute.edu.tw

Keywords: cultural property, database, data interpretation, digitizing, official integration data system

\begin{abstract}
Using digital technology for cultural heritage documentation is a global trend in the $21^{\text {st }}$ century. Many important techniques are currently under development, including 3D digital imaging, reverse engineering, GIS (Geographic Information Systems) etc. However, no system for overall management or data integration is yet available. Therefore, we urgently need such a system to efficiently manage and interpret data for the preservation of cultural heritages. This paper presents a digitizing process developed in Taiwan by the authors. To govern and manage cultural property, three phases of property conservation, registration, restoration and management, has been set up along a timeline. In accordance with the laws of cultural property, a structural system has been built for project management, including data classification and data interpretation with self-documenting characteristics. Through repository information and metadata, a system catalogue (also called data dictionary) (Figure 1) was created. The primary objective of the study is to create an integrated technology for an efficient management of databases. Several benefits could be obtained from this structural standard: (1) cultural heritage management documentation can be centralized to minimize the possibility of data re-entry resulting inconsistency, and also to facilitate simultaneous updating of data; (2) since multiple data can be simultaneously retrieved and saved in real time, the incidence of errors can be reduced; (3) this system could be easily tailored to meet the administrative requirements for the standardization of documentation exchanged between cultural properties institutions and various county and city governments.
\end{abstract}

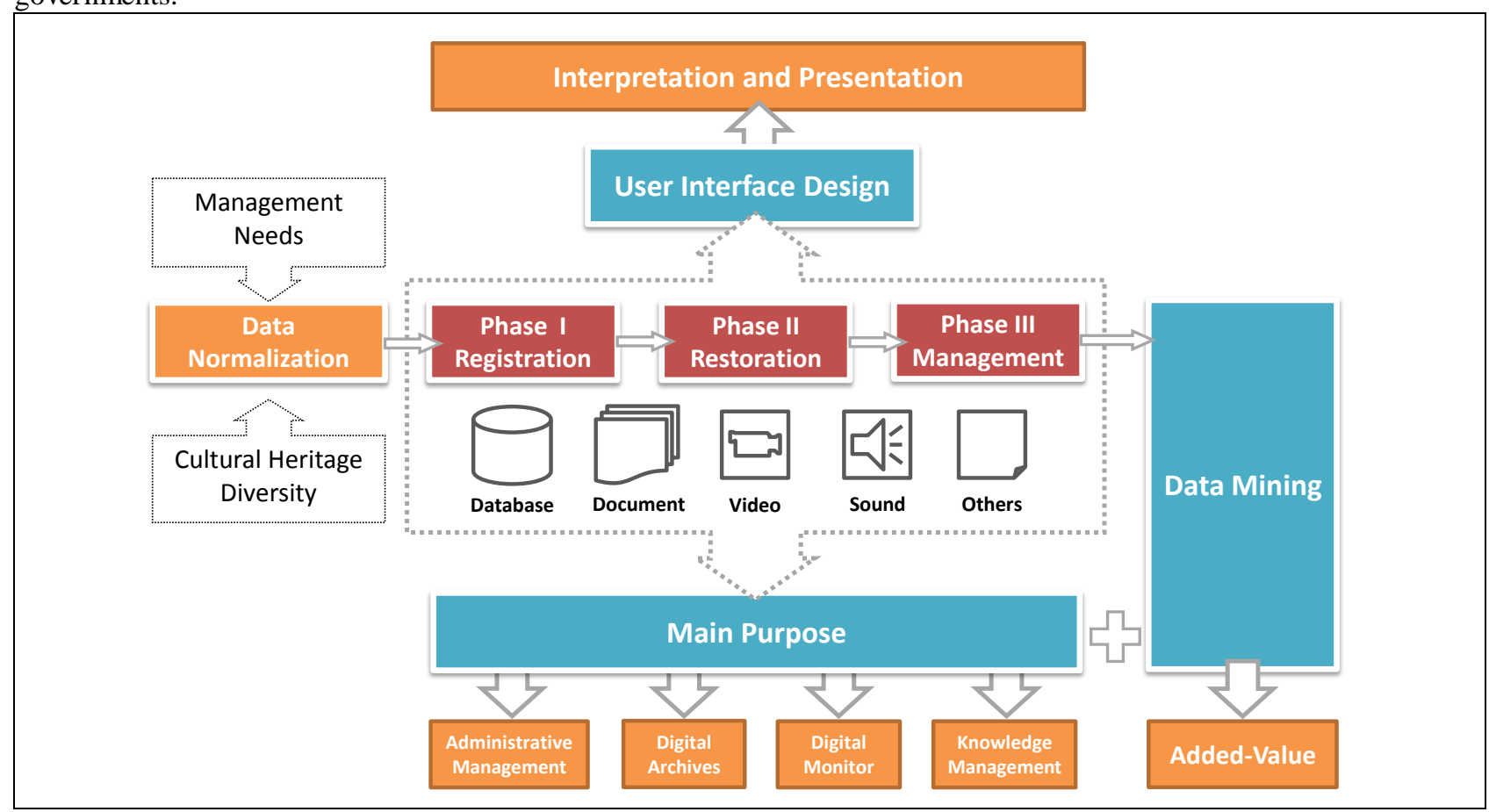

Figure 1: An integrative structure of data dictionary for Cultural Heritage 


\section{BACKGROUND}

Using digital technology for cultural heritage documentation is a global trend in the $21^{\text {st }}$ century. Many important techniques are currently under development, including 3D digital imaging, reverse engineering, GIS (Geographic Information Systems) etc. However, no system for overall management or data integration is yet available. Therefore, we urgently need such a system to efficiently manage and interpret data for the preservation of cultural heritages. Government as a key role of information management must be concerned and aware of the information provided to the public based on legal requirement. From the perspective of knowledge management, 4 phases are included: production, processing, dissemination and application. Concerning the diversity of heritage, the understanding and value assessment will give a help for the conservation interpretation and presentation.

\subsection{Goals}

This paper discusses standards of digitizing process to govern and manage cultural property in Taiwan. There are two main goals:

- To propose the standard for the production of information based on the requirement of diversity and management.

- To propose a DBMS (Database Management System) based on the KM (Knowledge Management) concept and providing an integrated service.

\subsection{Methods}

Two main methods were used in this study. Document method is analyzing and finding the characteristics of cultural heritages. The other is rapid prototype method which is integrated with information technology.

\subsubsection{Document Method}

1. To clarify the characters and value of cultural heritage by reviewing the international conventions, charters, documents.

2. To analyze the trend of digitizing technology for heritage documentation by reviewing the research papers.

3. To explore the requirement of cultural heritage management in Taiwan by reviewing legal documents and case studies.

4. To explore frameworks established with knowledge in cultural heritage by reviewing KM papers.

\subsubsection{Rapid prototype Method}

This paper uses the rapid prototype method to set up an integrated management system, evaluating its feasibility and convenience in future expansion by practice.

\section{THE CHARACTERISTIC AND VALUE OF CULTURAL HERITAGE}

It has been nearly 50 years since the inception of The Venice Charter in 1964 declaring the importance of conservation. Many significant concepts and practices have been promoted through various literatures after that.

\subsection{Value}

The Venice Charter points out that “......Its aim is to preserve and reveal the aesthetic and historic value of the monument and is based on respect for original materials and authentic documents. ......". Under the efforts of UNESCO, the 1972 Convention Concerning the Protection of the World Cultural and Natural Heritage developed a new era for the world heritage. An idea of OUV (Outstanding Universal Value) has been pointed out as the most important issue in the evaluation and preservation process of world heritage.

\subsection{Authenticity and Integrity}

The 2008 Operational Guidelines for Implementation of the World Heritage Convention declared that "To be deemed of outstanding universal value, a property must also meet the conditions of integrity and/or authenticity...". There are many international documents concerning these 2 issues. Such as:

1.The Washington Charter, 1987

2. The Nara document on Authenticity, 1994

3. Convention for the safeguarding of the intangible Cultural Heritage, 2003 
4. Charter on Cultural Routes, 2008

\subsection{Cultural diversity}

Many national or international documents are concerned with cultural diversity. Such as:

1. The Burra Charter, 1979

2. Universal Declaration on Cultural Diversity, 2001

3. Convention on the Protection and Promotion of the Diversity of Cultural Expressions, 2005

\subsection{Management and education}

In 2008, the $16^{\text {th }}$ general assembly of ICOMOS approved The Quebec Declaration on the preservation of the spirit of place. This declaration points out the importance of re-thinking, identifying the threats, safeguarding and transmitting the spirit of cultural heritage sites. The assembly also approved the Charter for the Interpretation and Presentation of Cultural Heritage Sites. The charter concludes the significance of "value" and proposes 7 principles as means of enhancing public appreciation and understanding of cultural heritage sites.

\subsection{Summary}

\subsubsection{The trend}

The ideas of cultural properties preservation in the early stage put great emphasis on physical preservation and supplemented with texts and images. In 1964, Article XVI of Venice Charter pointed out the importance of documentation and files. During the last 2 decades, concept of conservation had changed enormously with knowledge available and information easily obtained to all. The changes are reflected in following areas:

1. The expansion of heritage areas

(1) Expanded from tangible to intangible, promoting the preservation of intangible heritage.

(2) Expanded from the point to line to a plain, opening the path of cultural landscapes and cultural route as new research issue.

(3) Expanded from physical conservation to overall thinking of lifestyle.

2. Respecting for ordinary people

(1) Highlight diversity and cultural diversity.

(2) Highlight preservation of non-artistic (such as tools, materials, construction methods, technology, etc.).

(3) Highlight the rights and necessity of public knowledge and participation.

3. The development of active management

(1) To take notice of the basic file and its method of application and other issues.

(2) To take notice of management and related issues such as industry and community interaction.

(3) To take notice of management derived from economic, legal and other issues.

These changes touch on the content of knowledge and data as well as the process of dissemination and reception. In the $21^{\text {st }}$ century of digital era, how to use the highly popular system with effective management and delivery, communication and preservation of information, has become an unavoidable issue.

\subsubsection{The role of digital technology}

Computer and Internet have changed the way of knowledge dissemination through digital archives. Development of digital technology not only speeds up data collection, it also helps data management, dissemination and application. Preservation of cultural properties passes on human knowledge. Digital technology allows effective preservation of cultural properties and analysis and has become a trend all over the world. In 2008 , the $17^{\text {th }}$ session of the General Assembly of International Council on Monuments and Sites (ICOMOS) adopted the Declaration of Quebec (Quebec Declaration) pointed out that:

\footnotetext{
“..in the protection and promotion of world heritage monuments and sites. It also calls upon a multidisciplinary approach and diversified sources of information in order to better understand, manage and conserve context...Considering that modern digital technologies (digital databases, websites) can be used efficiently and effectively at a low cost to develop multimedia inventories that integrate tangible and intangible elements of heritage, we strongly recommend their widespread use in order to better preserve,
} 
disseminate and promote heritage places and their spirit. These technologies facilitate the diversity and constant renewal of the documentation on the spirit of place."

Cultural heritage interpretation and presentation of the Charter (The ICOMOS Charter for the Interpretation and Presentation of Cultural Heritage Sites) also pointed out that:

"Develop technical and professional guidelines for heritage interpretation and presentation, including technologies, research, and training. Such guidelines must be appropriate and sustainable in their social contexts"

These above-mentioned articles reiterate the importance of conserving, processing and presenting cultural heritage with digital technology. "Integrated technology", the invention from computation, has become an important digital technology since the 1980s. The business uses a lot of integrated systems such as Enterprise Resource Planning (Enterprise Resources Planning, ERP), with its aim to link all departments of the work flow (Operation Procedure), in order to achieve real-time communication and produce accurate information. Preservation of cultural properties includes knowledge of multiple fields such as architecture, sociology, history, surveying, structure, geography, art, etc. Working with various fields of experts and academics to co-research and investigate is important. Integrated digital technology has become an inevitable trend to be effectively applied to cultural properties conservation.

\section{THE TREND OF DIGITALIZATION RESEARCH OF CULTURAL PROPERTIES}

\subsection{The international trend of information digitalization}

Information production and dissemination of the development had a breakthrough in the late 20th century, thanks to the rapid development of computers and the impact of network technology. Government and non-governmental organizations around the world have conducted quite a few digital cultural heritages related projects and actions and made it an international issue of common concern, including:

1. Memory of the world program and E-Heritage driven by UNESCO since 1992.

2. American Memory driven by America since 1990 .

3. Visual Museum of Canada, VMC.

4. The number of library projects in Australia since 1996.

5. Europeane driven by European Union.

6. World Digital Library.

7. The Wikipedia.

8. Taiwan Digital Archives driven by Taiwan, ROC.

The above programs have the same characters in cultural theme, diverse participation, digital technology and longterm devotion.

\subsection{The key of digital technology}

Digital technology has two key issues which are knowledge management and implementation of the technology.

\subsubsection{Knowledge Management}

\section{Principle}

Knowledge management is an emerging field of research and the key points being how to deal with a large number of complex data and make it useful through effective management. The basic process of knowledge management can be divided into a four-cycled procedure including data production, information management, knowledge dissemination and application (Figure 2).

2. The professional gap and the necessity for integration

Digitization can quickly reduce the data access time. Interactive web tools such as WEB 2.0 provide better dissemination of information publishing platform. However, whether the data has been handled by standards of knowledge management and digitalization prior to its release or not isn't taken seriously. Neither are its management and application after. In recent years, the so-called "database" has turned into "data graveyard" which amply explains the crisis of lacking in standard. Cultural heritage and digital technology originally belong to two different fields of 
expertise. With the demand for digitization and knowledge management framework, integration of the two professional fields is necessary.

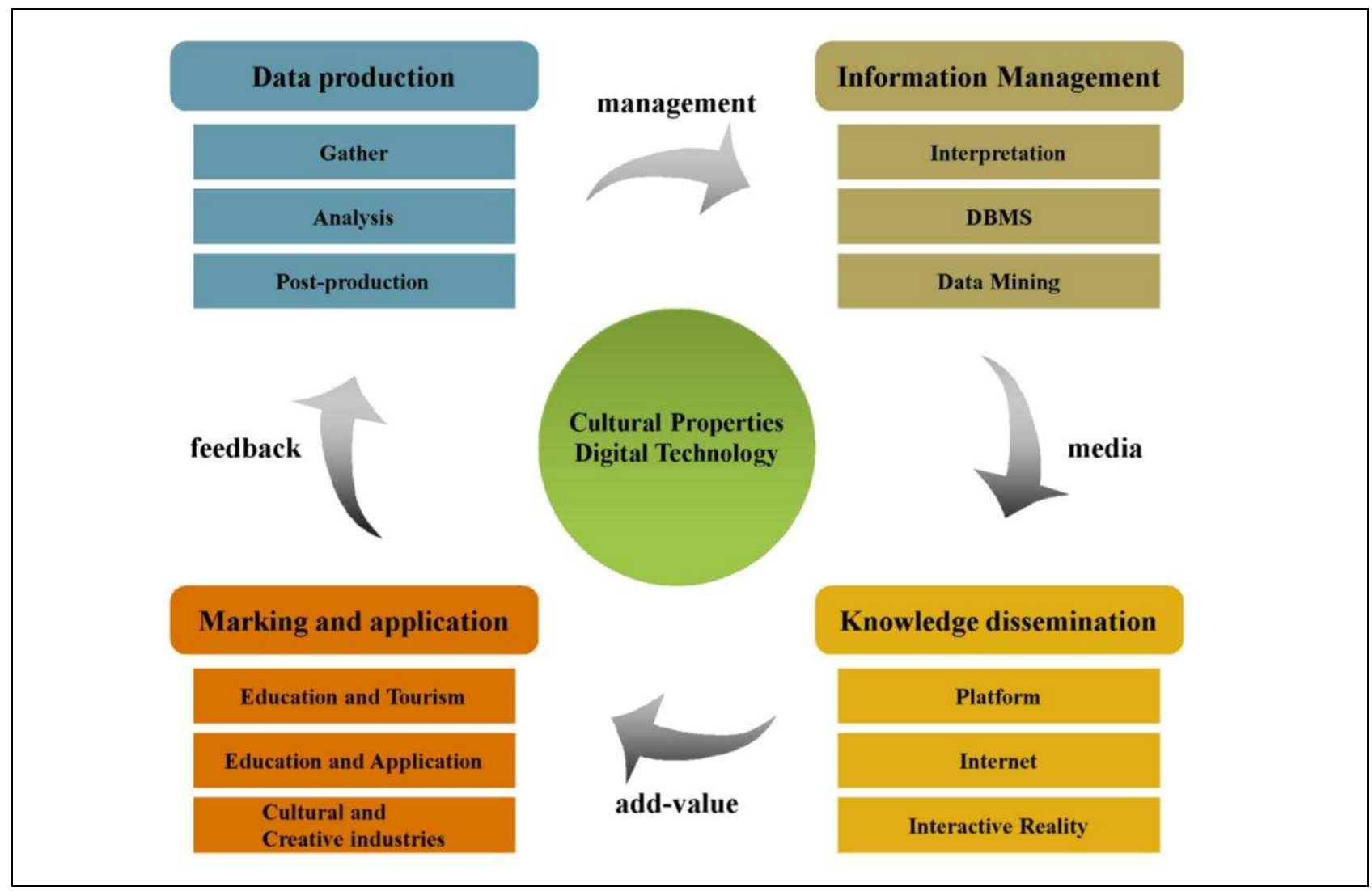

Figure 2: Four-cycled knowledge management procedure

\subsubsection{Digital implementation technology}

Digitization of cultural properties is a new technology. Many research results have been presented and shared at important international seminars. The topics include:

1. Data acquisition and analysis: laser scanning (ground, from air), photogrammetry, remote sensing, etc.

2. Data Standard: Standard, pointer, intellectual property, etc.

3. Data transmission: transmission technology, Web, GIS, etc.

4. Data applications: environmental monitoring, disaster prevention, education, enterprise, etc.

During the past decade, several issues about cultural heritage were discussed repeatedly. They not only explained the digital technologies that were still progressing, but also reflected the diverse digital technologies and the diverse characteristics.

\subsection{Management Purpose}

The purpose of preservation of cultural heritage is to sustain cultural properties through public understanding. In order to provide convenient and accurate information, a well-constructed and integrated management system is needed for handling vast and diverse data. There are two points of views about data management in the past. One is on demandoriented administration (Policy-orientated), the other is public-oriented (Public-orientated). Government played an important role in preservation of cultural properties heritage. Combined with public opinions, the study promotes a digitalized standard for management of cultural heritages. From the perspective of knowledge management, this study provides a research management framework shown in Figure 3.

1. The diversity of cultural heritage properties should be taken into account on the level of management, interpretation and presentation and other needs. 
2. Considering life cycle of administrative procedures for cultural heritage preservation, data for the integrative management system should be divided into registry, repair and management in three dimensions.

3. The database established should meet the demands of the public and the government for its application and dissemination.

4. The integrative management system should take into account the future possibility of expansion and added value.

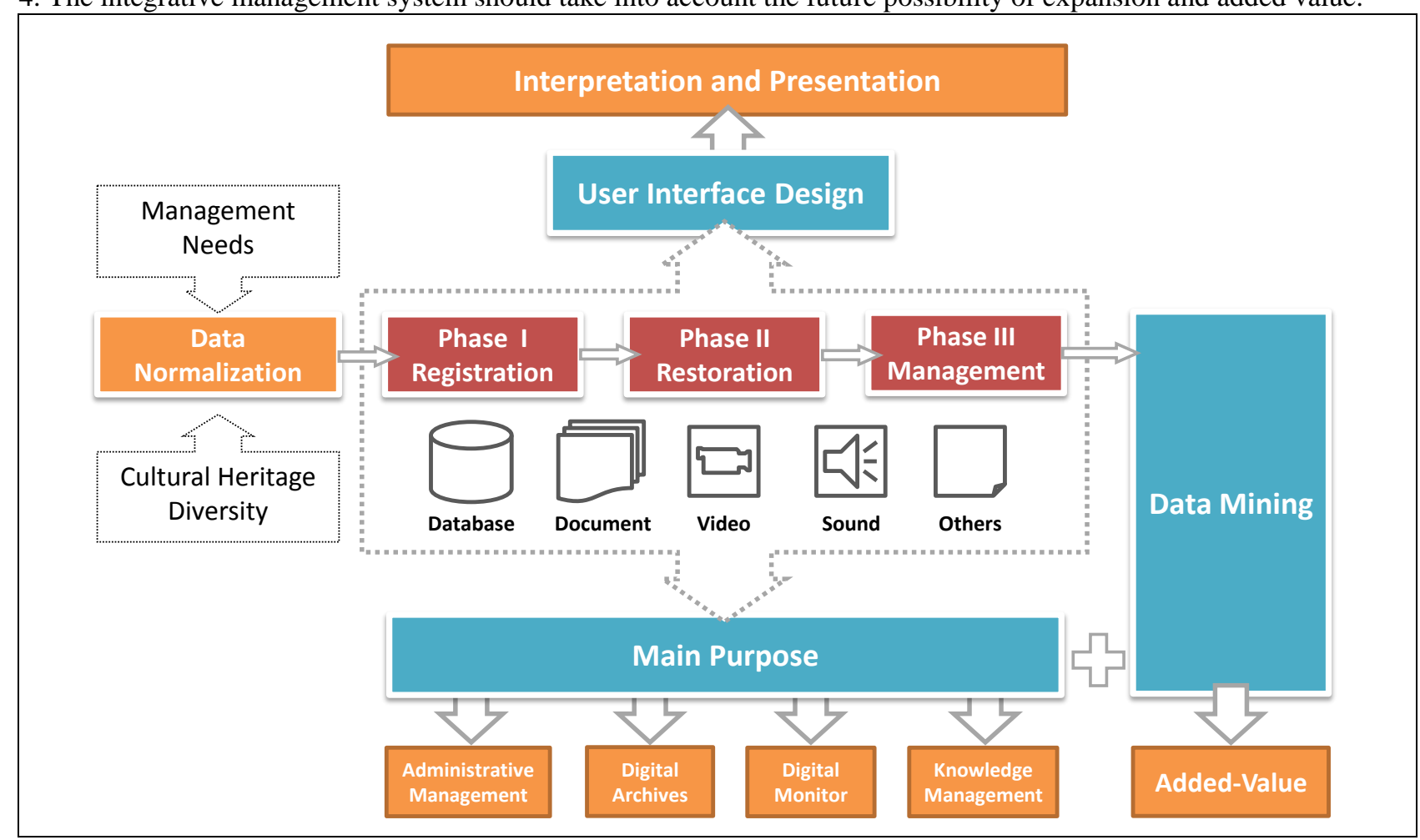

Figure 3: An integrative structure of data dictionary for Cultural Heritage

\section{A TENTATIVE MANAGEMENT SYSTEM FOR TAIWAN}

\subsection{Background}

Taiwan has had its Cultural Heritage Preservation Act (CHP. ACT.) since 1982. In accordance with the influence of international movement, the act has been amended and promulgated for 7 times. In 2005, a new act with articles was taken effect, an information system and data tables were set together with this new act, and a new era of digital management for cultural heritage began. However, this system mainly focused on the first phase of conservation. Almost all the tables dealt with basic information and registration process of monuments while lacking in information of restoration and management (Figure 4). Based on this system, an official database for the monument was established in 2008. As the former planning was in want of an integrative concept, its database was inefficient and is under rearranging at the moment.

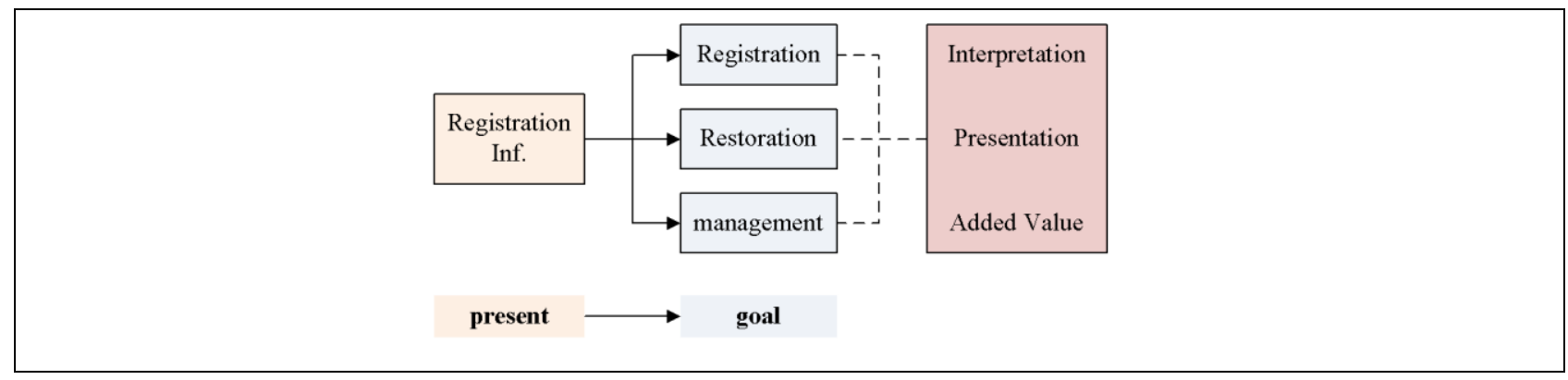

Figure 4: The idea of an integrative DBMS in Taiwan 


\subsection{Requirement analysis}

\subsubsection{Action}

According to the CHP Act, 2005 the basic information for the management can be shown as Figure 5.Three issues can be described in advance from Figure 5.

1. Act and accompanying rules provide a clear procedure which needed to identify the process of preservation. It can be taken as basic information for the database.

2. The required information in 3 different phases are necessary to help the management with their importance.

3. With database management system (DBMS), an efficient convenient platform for the management of cultural properties can be provided.

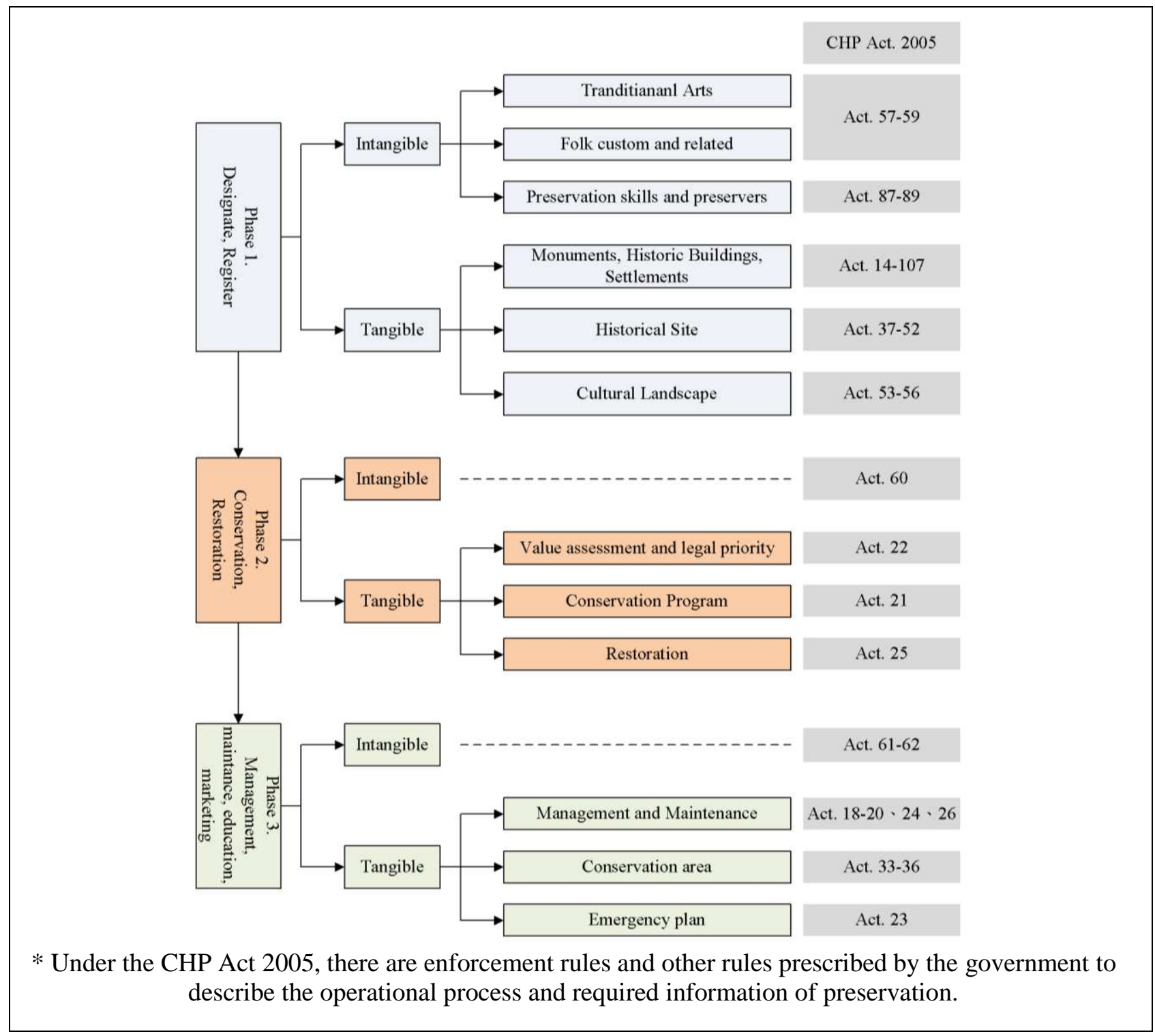

Figure 5: The flowchart (intangible and tangible) of 3 phases of information managements

\subsection{The principles of data structure}

\subsubsection{Information and data interpretation}

Considering the life cycle of data and different types of data usage, data must be stored at different servers according to different data types to provide appropriate services. The study uses metadata to provide communication channels between different types of data servers. Metadata were generated automatically by DBMS and stored in public 
dictionary that other DBMS can access and query these metadata. For some specific usage, metadata can be added some fields in demand to facilitate follow-up data query purposes.

\subsubsection{Normalization}

Analysis of information obtained by the previous stage can be divided into categories, text, images, sounds, images and other types. In order to take into account the contents of the database consistency and accuracy, every field data that were inputted by user must be normalized in order to improve efficiency and avoid unnecessary storage space and waste of bandwidth in transmission of data and future consumption. With database management system construction, different tables can be related through a unique code. This study was set up with Microsoft SQL 2008 system and database related model (Figure 6).

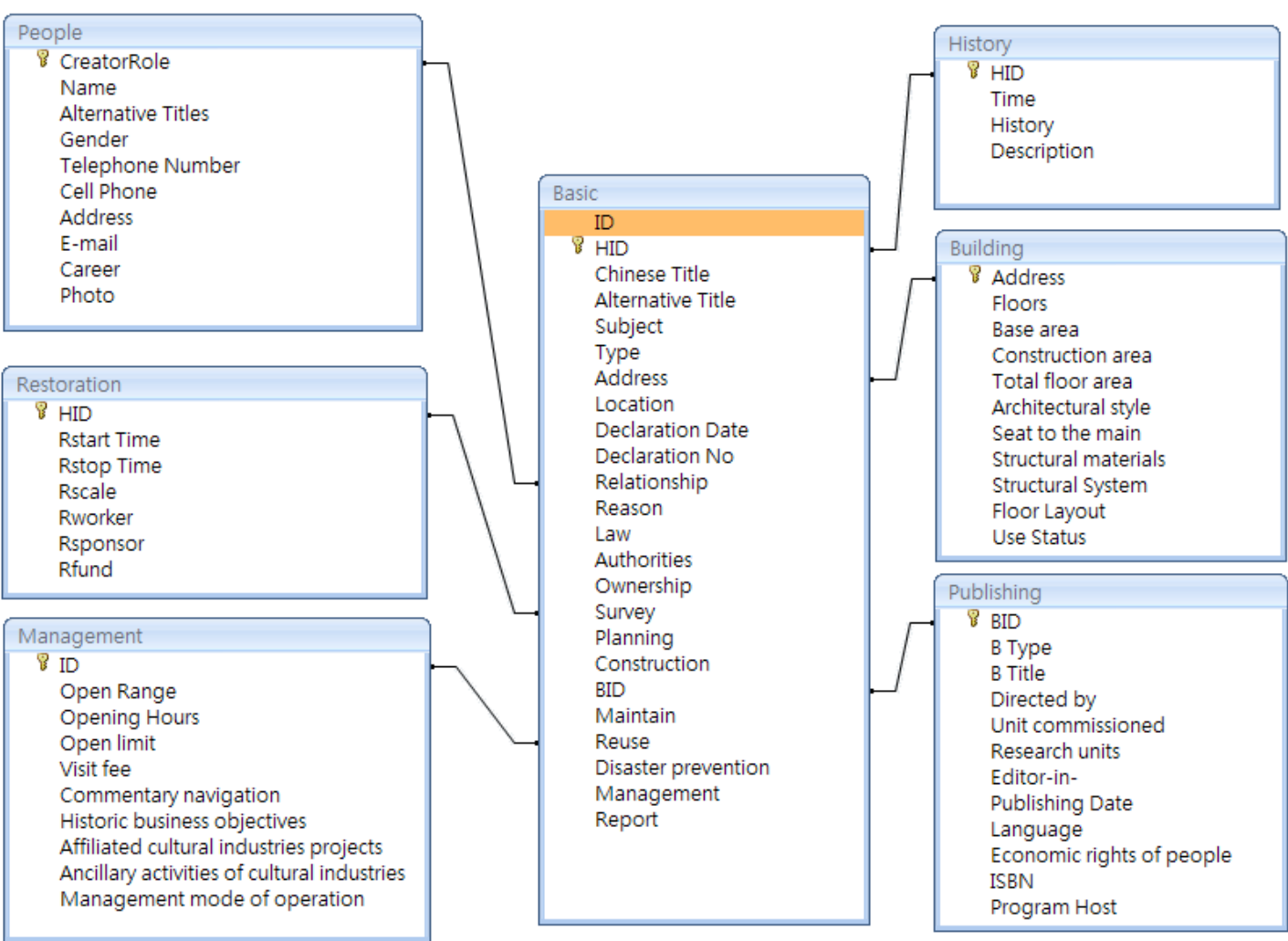

Figure 6: Database Related Model

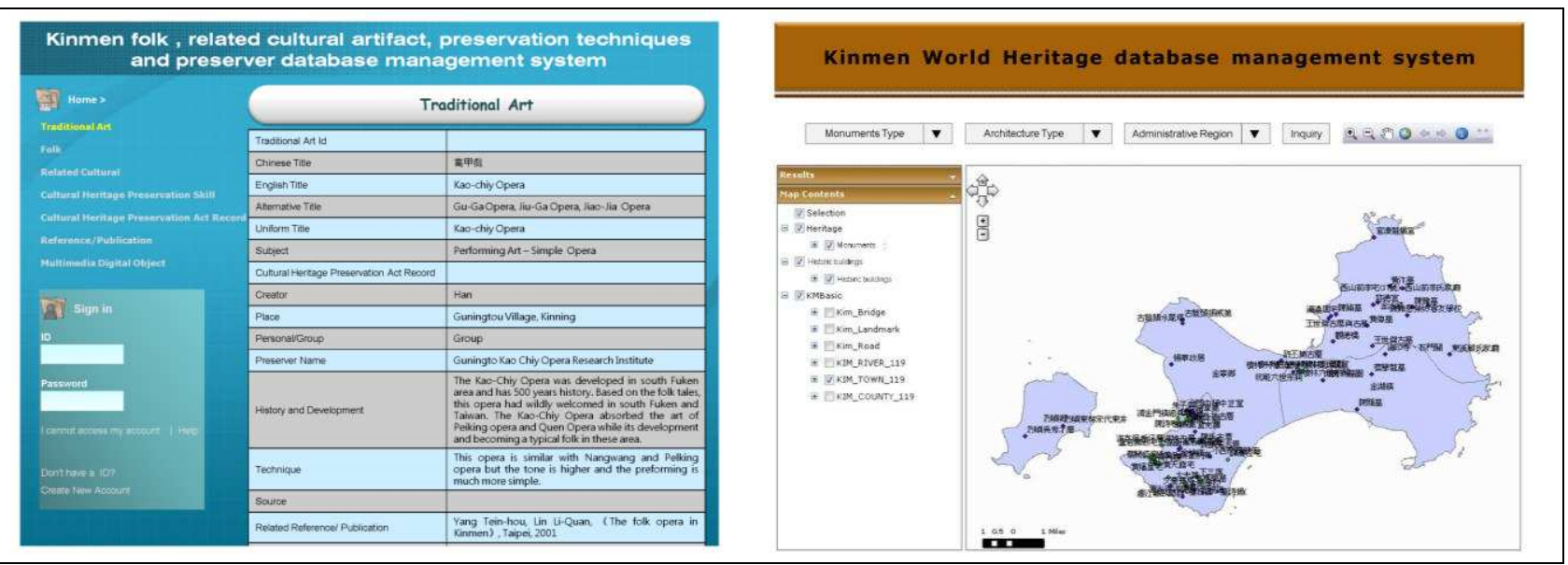

Figure 7: Integrative Management System 


\subsection{System Sample}

This study uses rapid prototype method to establish an integrated database management system. System demo screen. (Fig.7)

\section{DISCUSSION \\ 5.1 Result}

Several benefits could be obtained from this structural standard: (1) cultural heritage management documentation can be centralized to minimize the possibility of data re-entry and resulting inconsistency, it also can facilitate simultaneous updating of data; (2) since multiple data can be simultaneously retrieved and saved in real time, the incidence of errors can be reduced; (3) this system could be easily tailored to meet the administrative requirements for the standardization of documentation exchanged between cultural properties institutions and various county and city governments.

\subsection{The goal of this system}

The $17^{\text {th }}$ ICOMOS general assembly (2011) will take "Heritage: Driver of Development" as a main issue. This concept identifies that the preservation and reuse of cultural heritage should play an active role and extends their sight toward an integrative field for the creation of tomorrow's world. For the convenience of recording, documentation and application, the development of digital techniques has become most important in support of this goal. Corresponding techniques such as GIS, 3D Laser scan, Photogrammetry, Remote Sensing, DBMS etc., have been applied in the field of conservation. On the other hand, the main content of heritage and applications with added value is another important issue. For the documentation and application information, building an integrative frame work is needed. Besides meeting the basic recording and management requirements, how to open to public, how to apply with added value and what new business model might evolve should be thought through while setting standards.

\subsection{The contributor and user}

Conservation of cultural heritage is a work of highly integration. For accuracy, efficiency and safety, it would be better for the government to take the main responsibility for the establishment and management of Centralized DBMS. Private sectors and NGO should play an active role in such process. As to open this DB to the public, the accuracy, timeliness, information security, intelligent property right, etc., should take into consideration.

\subsection{Main issues of the standardization} 5.4.1 The content of information

Each monument holds vast and various data. It's essential to collect and sort out data efficiently according to needs then come up with an appropriate interpretation and presentation. Regarding the diversity of cultural heritage together with requirement of management and added value this research points out that holding the content of monument is the key issue for the DBMS.

\subsubsection{The integration of different format}

Audio and visual are two main types of digital information that are developed into various formats. These formats were modified by different software and mostly controlled by commercial companies. To build a convenient platform for the exchange, information of different formats is an important work. Besides that, a cloud technique developed for the management of vast digitized information is another key issue, in this field.

\subsection{The extension map}

Using digital techniques as a powerful tool for managing, reusing, and extending value of Cultural Heritage has become an inevitable trend in the $21^{\text {st }}$ century. Besides the stakeholder, the participation team should have a wide range of experts. From digitization point of view, an extension map for the integration technique was proposed for the next step (Figure 8) . 


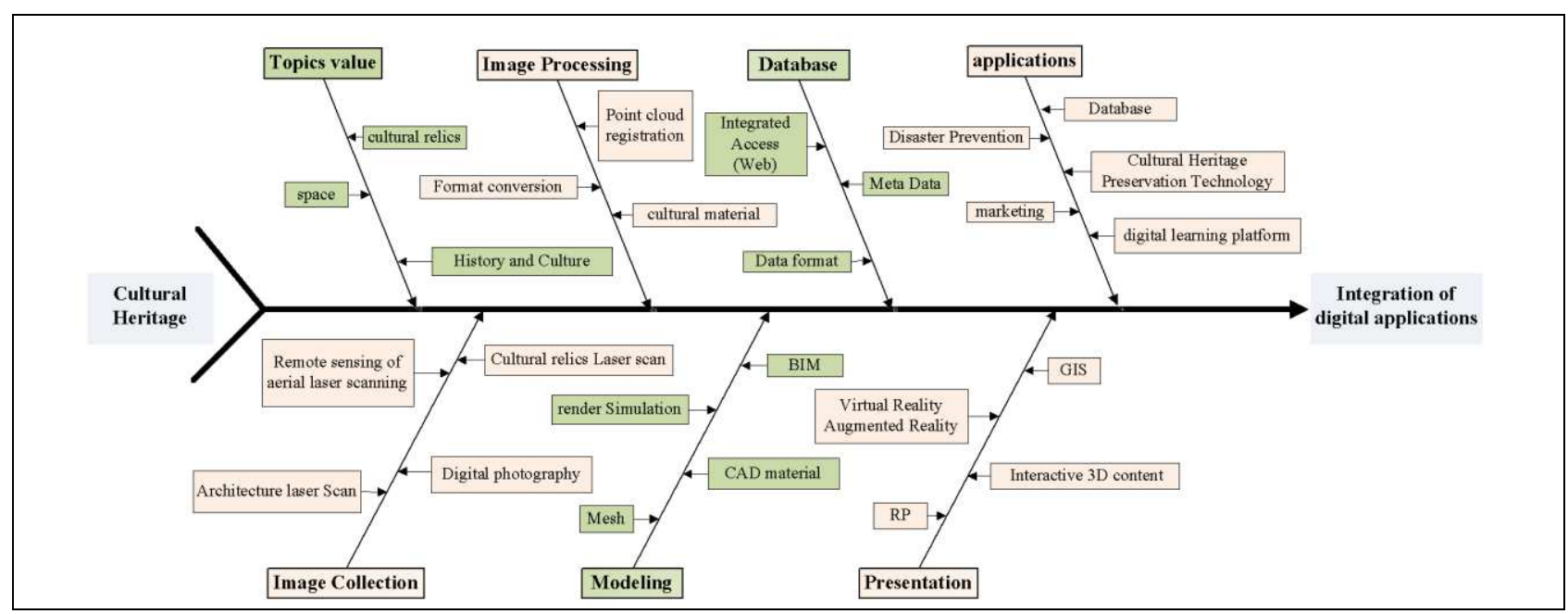

Figure 8: The diagram of digitizing technique

\section{ACKNOWLEDGEMENT}

This research was supported by NSC 99-2632-H-163-001-MY2

\section{REFERENCES}

[1] UNESCO World Heritage Center (2008), Operational Guidelines for Implementation of the World Heritage Convention.

[2] Jukka Jokilehto(1999). A History of Architectural Conservation. pp.290.

[3] Prepared by the National Library of Australia (2003), GUIDELINES FOR THE PRESERVATION OF DIGITAL HERITAGE 